\title{
DESENVOLVIMENTO DE FORMULAÇÕES BISCOITOS TIPO COOKIES COM ADIÇÃO DE FARINHA DE FEIJÃO CAUPI BRS XIQUEXIQUE
}

\section{DEVELOPMENT OF FORMULATIONS BISCUITS TYPE COOKIES WITH ADDITION OF BEAN CAUPI BRS XIQUEXIQUE}

\author{
Silmara Dayane Fiorentin¹, Fabiane Ribeiro Teixeira¹, Sabrine Zambiazi da Silva 2, \\ Daniela Miotto Bernardi ${ }^{3}$, Silvia Maria Viana dos Santos ${ }^{4}$, Frederico Rodrigues \\ Lovato $^{5}$ \\ ${ }^{1}$ Nutricionistas Centro Universitário Fundação Assis Gurgacz (FAG), ${ }^{2}$ Nutricionista. Mestre em \\ Engenharia Agrícola, professora do Centro Universitário (FAG), ${ }^{3}$ Nutricionista, Doutora em alimentos \\ e Nutrição, professora do Centro Universitário (FAG), ${ }^{4}$ Nutricionista, Graduanda em Vigilância \\ Sanitária, Cascavel- PR, ${ }^{5}$ Engenheiro Químico - FUNDETEC, Cascavel - PR \\ *Autor correspondente: sazambiazi@yahoo.com.br, https://orcid.org/0000-0001-6931-3601
}

\begin{abstract}
RESUMO
O feijão caupi é um importante alimento para a população brasileira. Além do baixo custo, é uma fonte completa de carboidratos, proteínas e fibras, e, quando biofortificado, melhorado geneticamente com teores elevados de ferro e zinco, desempenha papel fundamental ao organismo e na manutenção da saúde. Este trabalho tem por objetivo utilizar a farinha de feijão caupi biofortificada para a elaboração de biscoitos tipo cookies, auxiliando no combate de carências desses micronutrientes, com melhor valor nutricional, e, através da análise sensorial, avaliar a aceitabilidade do produto. Foram desenvolvidas três formulações, uma padrão: (F1) $15 \%$ (F2) e 30\% (F3) de adição de farinha de feijão caupi, e, então realizadas as análises: microbiológica, físico-química e sensorial. Os resultados microbiológicos apresentam-se conforme a legislação. A análise físico-química mostrou que umidade, proteína, lipídios e fibras tiveram diferença significativa nas formulações. Os teores de ferro e zinco também diferiram entre as amostras. $\mathrm{Na}$ análise sensorial os atributos que diferiram estatisticamente foram aceitação global e sabor. Logo, os biscoitos tipo cookies com adição da farinha de feijão caupi biofortificados, possuem fontes de ferro e zinco necessárias para suprir as necessidades recomendadas, como opção saudável e nutritiva, sendo uma opção viável para a indústria de produtos alimentícios. Órgãos Financiadores: Fundação para o Desenvolvimento Científico e TecnológicoFUNDETEC.
\end{abstract}

Palavras-chave: biscoito tipo cookies, feijão caupi, biofortificado.

\begin{abstract}
Cowpea beans are an important food for the Brazilian population. In addition to the low cost, it is a complete source of carbohydrates, proteins and fibers, and when biofortified, improved genetically with high levels of iron and zinc, plays a fundamental role in the organism and in maintaining health. The objective of this work is to use biofortified cowpea flour for the preparation of cookie type cookies, helping to combat deficiencies of these micronutrients, with better nutritional value, and, through sensorial analysis, to evaluate the acceptability of the product. Three formulations were developed: (F1) 15\% (F2) and 30\% (F3) of cowpea flour addition, and then the microbiological, physicochemical and sensorial analyzes were carried out. The
\end{abstract}


microbiological results are in accordance with the legislation. Physical-chemical analysis showed that moisture, protein, lipids and fibers had a significant difference in the formulations. The iron and zinc contents also differed between the samples. In sensory analysis the attributes that differed statistically were global acceptance and taste. Cookies, with the addition of biofortified cowpea flour, have iron and zinc sources necessary to meet the recommended needs, as a healthy and nutritious option, being a viable option for the food industry.

Funding Agencies: Foundation for Scientific and Technological DevelopmentFUNDETEC.

Keywords: cookie type cookies, cowpea beans, biofortified.

\section{INTRODUÇÃO}

A biofortificação do Feijão caupi em relação aos grãos comuns, apresenta além de proteína, carboidratos, lipídeos e fibras, maior teor de minerais, como ferro e zinco. Este melhoramento surgiu como uma alternativa para combater carências nutricionais, por ser uma leguminosa bastante consumida pela população (CARVALHO et al., 2011; NUTTI, 2011).

A carência nutricional de ferro está relacionada ao surgimento de anemia e de sintomas como fraquezas, tonturas, diminuição da capacidade respiratória, fadiga e cansaço e problemas de crescimento. Entre as funções do ferro destaca-se: transporte e armazenamento de energia no transporte da cadeia de elétrons, transporte e armazenamento de oxigênio e participação de várias reações metabólicas (LEMOS et.al, 2012; LEITÃO e OLIVEIRA, 2016). A Organização Mundial da Saúde (OMS) estima que $66 \%$ da população mundial têm carências de ferro e cerca de $40 \%$ apresentam anemia, sendo eles: idosos, crianças em fase pré-escolar, adolescentes, gestantes e lactentes (LANDIM 2013).

Já a deficiência do zinco está associada à mortalidade e gravidade em problemas infeciosos, pois ocasiona diminuição do sistema imune, problemas respiratórios, perda de apetite e problemas de crescimento, principalmente em crianças, nas quais a necessidade pode estar aumentada. $O$ zinco desempenha diversas funções no corpo humano; participa como cofator de mais de 200 enzimas envolvidas na manutenção de importantes vias metabólicas no organismo, exerce funções como a participação no processo de diferenciação celular e crescimento estrutural, atua no sistema imunológico e ajuda na cicatrização (PEDRAZA e SALES, 2015).

O Desenvolvimento de alimentos biofortificados com maior teor de micronutrientes é de extrema relevância e vem crescendo cada vez mais devido ao baixo custo e pelo seu valor nutricional, atuando na prevenção e correção de carência de micronutrientes (FISBERG e VELLOZO, 2010). Melhorar a qualidade nutricional de produtos já inseridos no cotidiano e nos hábitos alimentares dos indivíduos é uma forma de atender suas necessidades, contribuindo assim para um estilo de vida mais saudável, oferecendo ao consumidor uma nova opção de produto através da elaboração de alimentos à base de cultivares biofortificadas (FROTA et.al., 2010; CARDOSO-SANTIAGO et.al., 2001; MOREIRA-ARAÚJO et.al., 2002). Deste modo, o presente trabalho tem por objetivo utilizar a farinha de feijão caupi biofortificado para a elaboração de cookies com maior teor de ferro e zinco, visando auxiliar no combate as carências destes micronutrientes e através da análise sensorial avaliar a aceitabilidade do produto. 


\section{MATERIAIS E MÉTODOS}

\subsection{MATÉRIA-PRIMA}

Os grãos de feijão caupi (BRS xiquexique) utilizados como matéria prima para a elaboração dos cookies foram cedidos pela Fundação para o Desenvolvimento Cientifico e Tecnológico (FUNDETEC), localizada na cidade de Cascavel-PR, e os demais ingredientes utilizados nas formulações foram adquiridos no comércio local da cidade.

\subsection{OBTENÇÃO DA FARINHA}

Para a obtenção da farinha de feijão caupi (BRS xiquexique), os grãos foram deixados por meia hora em remolho, com temperatura de $80^{\circ} \mathrm{C}$, para então retirar 0 tegumento. Em seguida, foram levados para a estufa (Quimis Q317m) por 24 horas, a $50^{\circ} \mathrm{C}$ (FROTA, 2010). Após este processo foi feita a moagem do grão no moinho Willey TE-650 (Tecnal), para obter-se a farinha.

\subsection{FORMULAÇÕES DOS COOKIES}

As formulações foram desenvolvidas através de pré-testes realizados na Fundetec, no setor da AGROTEC (Escola Tecnológica Agropecuária), utilizando como base receitas convencionais de cookies. Dessa forma, foi possível preparar diferentes formulações com diferentes quantidades de farinha de feijão caupi (BRS xiquexique), variando as proporções dos ingredientes, bem como o tempo de forno e a temperatura, até obter-se as formulações viáveis para a seleção.

Para o preparo das três formulações dos cookies foram utilizados os seguintes ingredientes: farinha de feijão caupi (BRS xiquexique) biofortificada, farinha de trigo integral, farinha de trigo, açúcar mascavo, manteiga, ovos, fermento em pó, essência de baunilha, aveia em flocos, coco ralado, chocolate alfarroba em pó, sal e bicarbonato, sendo FP (formulação padrão), F15\% (formulação com 15\% da farinha de feijão) e F30\% (formulação com 30\% de farinha de feijão), como mostra a Tabela 01 a seguir.

Tabela 01. Formulação dos biscoitos tipo cookies com adição de farinha de feijão caupi biofortificado em porcentagens:

\begin{tabular}{lccc}
\hline \multicolumn{1}{c}{ Ingredientes } & FP\% & F15\% & F30\% \\
\hline Farinha de Feijão & 0 & 2,57 & 5,15 \\
Farinha de Trigo Integral & 18,96 & 17,53 & 16,11 \\
Farinha de Trigo & 15,37 & 14,22 & 13,07 \\
Manteiga & 17,91 & 17,91 & 17,91 \\
Ovos & 7,46 & 7,46 & 7,46 \\
Açúcar Mascavo & 10,45 & 10,45 & 10,45 \\
Essência de Baunilha & 0,90 & 0,90 & 0,90 \\
Chocolate Alfarroba em Pó & 5,97 & 5,97 & 5,97 \\
Coco Ralado & 10,45 & 10,45 & 10,45 \\
Aveia em Flocos & 10,45 & 10,45 & 10,45 \\
Fermento em pó & 1,49 & 1,49 & 1,49 \\
Bicarbonato & 0,30 & 0,30 & 0,30 \\
Sal & 0,30 & 0,30 & 0,30 \\
\hline
\end{tabular}




\subsection{ELABORAÇÃO DA MASSA}

Os ingredientes foram devidamente separados e pesados em uma balança de precisão da marca Shimadzu (UX620H), de acordo com cada formulação. $\mathrm{Na}$ sequência foi feita a homogeneização da manteiga com o açúcar mascavo em uma batedeira até criar uma massa fofa e clara. Os ovos e a essência de baunilha foram adicionados em seguida e batidos novamente até se incorporar com a manteiga e o açúcar.

Logo após, a quantidade de farinha de cada formulação foi adicionada aos poucos. O sal, o bicarbonato e o fermento também foram adicionados juntos a massa e batidos até que se misturassem, sendo então colocado por último o coco, a aveia em flocos e o chocolate alfarroba. Posteriormente, a massa foi porcionada em pequenas bolinhas com aproximadamente $10 \mathrm{~g}$ cada, cortadas com o cortador de inox (Walpan 2,9x 4) e assadas em forno pré-aquecido, sobre papel manteiga, por aproximadamente 6-9 minutos, em temperatura de $180^{\circ} \mathrm{C}$, como mostra a figura 1 .

Pesagem dos ingredientes<smiles>C1CCCC1</smiles>

Homogeneização dos ingredientes

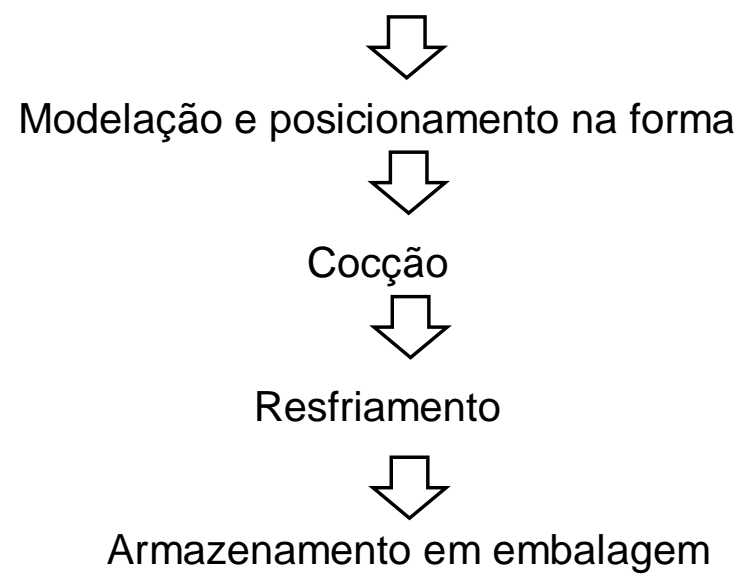

Figura 1. Fluxograma do processamento dos cookies de Farinha Feijão Biofortificada

\subsection{ANÁLISES MICROBIOLÓGICAS}

As análises microbiológicas foram feitas no laboratório da FUNDETEC. As análises realizadas foram de Coliformes Totais, Coliformes a $45^{\circ} \mathrm{C}$ Estef. Coag. Positiva, Salmonella, conforme descrita na resolução oㅡ 12, de 02 de janeiro de 2001 da Anvisa, seguindo a metodologia descrita em Silva et al. (2010). 


\subsection{COMPOSIÇÃO CENTESIMAL}

As análises Físico-químicas dos Cookies foram realizadas no laboratório da FUNDETEC, em triplicata, seguindo as metodologias descritas em IAL (2008). Foram avaliados os carboidratos, proteínas, lipídeos, cinzas, umidade, fibras, ferro e zinco. O teor de cinzas foi analisado após a incineração das amostras em mufla SP-1200 (SP Labor) a $550^{\circ} \mathrm{C}$; a umidade foi determinada em secagem direta em estufa 4023D (Nova Ética) a $105^{\circ} \mathrm{C}$, até obter peso constante; as proteínas foram analisadas pelo método de micro kjeldahl, com fator de conversão de 6,25; o teor de lipídios deu-se em um extrator de soxhlet INV-06 (Inova) com reagente éter de petróleo; o carboidrato foi obtido pela diferença dos demais; o valor calórico foi calculado de acordo com fatores de conversão e a fibra bruta foi determinada por hidrólise ácido e básico. Os valores de ferro e zinco foram analisados em um equipamento de espectrometria de emissão por plasma de argônio indutivamente acoplado (ICP-OES).

\subsection{ANÁLISE SENSORIAL}

A realização da análise sensorial foi aprovada pelo comitê de ética em pesquisa com seres humanos da Fundação Assis Gurgacz, sob o parecer do número 1.879.793. Antes de iniciar a análise os provadores foram esclarecidos dos procedimentos e convidados a assinar o Termo de Consentimento Livre e Esclarecido (TCLE) (APÊNDICE 01). A análise foi realizada em cabines especificas de análise sensorial em uma faculdade na cidade de Cascavel, com 122 provadores não treinados, de ambos os sexos. As amostras foram servidas aos participantes em blocos aleatórios, como descrito em MACFIE (1989). As formulações foram oferecidas em recipientes descartáveis codificados por três dígitos, com quantidades padronizadas de $20 \mathrm{~g}$, sendo disponibilizado também um copo com água mineral aos participantes para que pudessem fazer a limpeza do palato entre o intervalo das amostras.

Os provadores avaliaram a impressão global, aparência, aroma, sabor e textura das amostras dos cookies através de uma fixa de uma escala hedônica estruturada de nove pontos cujos números correspondiam 1 para desgostei muitíssimo e 9 gostei muitíssimo (APÊNDICE 02) (DUTCOSKY, 2013). Também se avaliou a intenção de compra por meio de uma escala estruturada de 5 pontos, cujos extremos correspondiam à certamente compraria (5) e certamente não compraria (1).

O Índice de aceitabilidade das amostras foi calculado a partir da expressão: IA $(\%)=A \times 100 / B$, onde, $A=$ nota média obtida para o produto e $B=$ nota máxima dada ao produto.

\subsection{ANÁLISE ESTATÍSTICA}

As análises físico-químicas e sensoriais dos cookies foram obtidas por ANOVA, considerando nível de significância de $5 \%$ e pelo teste de Tukey, a fim de verificar a diferença entre as formulações através do programa Microsoft Excel.

\section{RESULTADOS E DISCUSSÕES}

\subsection{ANÁLISE MICROBIOLÓGICA}

Os resultados da análise microbiológica dos cookies assados estão apresentados na Tabela 02. 
Tabela 02. Análises microbiológicas realizadas em amostras de cookies com adição de Farinha de feijão caupi (Brs xiquexique) Biofortificada:

\begin{tabular}{llll}
\hline \multicolumn{1}{c}{ Microrganismos } & F1 & F2 & F3 \\
\hline Coliformes Totais (NMP/g) & $<3,0$ & $<3,0$ & $<3,0$ \\
Coliformes Termotolerantes & $<3,0$ & $<3,0$ & $<3,0$ \\
Staphylococcus aureus (UFC/g) & $<10^{2}$ & $10^{2}$ & $10^{2}$ \\
Salmonella (sp/25g) & Ausente & Ausente & Ausente \\
\hline
\end{tabular}

Os dados microbiológicos mostraram que os produtos desenvolvidos apontam para resultados compatíveis com os exigidos, conforme a Resolução RDC no 12, de 02 de janeiro de 2001 da Anvisa. Nas análises a Salmonella sp esteve ausente em todas as formulações. Staphylococcus aureus analisados apontaram em todas as preparações $<10^{2}$. Coliformes termotolerantes a $45^{\circ} \mathrm{C}$ e mostraram-se $<3,0$ em todas as preparações. Os resultados de coliformes totais apontaram $<3,0$ nas três preparações. Sendo assim, o produto desenvolvido não traz nenhum risco aos seus consumidores.

Avaliar a quantidade e os tipos de microrganismos que podem estar presentes nos alimentos é fundamental para avaliar as condições de higiene em que o alimento foi produzido, pois o alimento pode oferecer risco à saúde daqueles que o consomem. Além disso, é importante para que se possa verificar se os padrões microbiológicos nacionais estão sendo atendidos (FRANCO e LANGARDRAF, 1996).

\subsection{COMPOSIÇÃO CENTESIMAL}

Para a comprovação da análise centesimal do produto pode-se observar os dados conforme a tabela 03 a seguir.

Tabela 03. Resultados da análise físico química das amostras de cookies com adição de farinha de feijão (Brs xiquexique) Biofortificada:

\begin{tabular}{|c|c|c|c|}
\hline Ensaios & FP & F15\% & F30\% \\
\hline Umidade $(\mathrm{g})$ & 12,95 & 12,86 & 10,92 \\
\hline Proteína (g) & 8,88 & 10,71 & 11,31 \\
\hline Carboidratos (g) & 57,06 & 56,51 & 50,17 \\
\hline Gorduras Totais (g) & 19,41 & 16,9 & 16,9 \\
\hline Cinzas (g) & 2,25 & 2,21 & 2,16 \\
\hline Fibra $(\mathrm{g})$ & 11,7 & 25,9 & 33,6 \\
\hline Ferro $(\mathrm{g})$ & 0,9 & 1,2 & 2,3 \\
\hline Zinco $(\mathrm{g})$ & 3,2 & 7,8 & 13,1 \\
\hline
\end{tabular}

Os resultados demonstram que as formulações obtiveram resultados de 12,95 a 10,92 \% de umidade. A resolução prevista para esse critério, RDC no 263 de 2005, aponta que o máximo tolerável para esse indicador é de até 15\%. Dessa forma, com os resultados obtidos pode-se afirmar que o tempo de vida útil do produto, bem como sua crocância está adequado quanto aos produtos comerciais.

Para o parâmetro de proteínas, a pesquisa apresentou resultados de $8,88 \mathrm{~g}$ para a FP 10,71g para F15\% e 11,31g para F30\%. Landim et.al (2013), desenvolveu uma formulação de biscoito com a adição de farinha de feijão caupi, sendo uma com farinha padrão (FFC) e outra com a adição de farinha de feijão caupi (FFCb). Em seu estudo, similar a esse, encontrou $24,2 \%$ de proteína para a formulação (FFC) e $23,3 \%$ 
na formulação (FFCb), mostrando assim que os biscoitos feitos com a farinha padrão obtiveram maior concentração de proteínas. Ainda no estudo do autor, pode-se notar que o teor de umidade da formulação com farinha de feijão convencional apresentou média de 9,8 pela formulação com farinha convencional (FFC) e 7,92 para a formulação de farinha de feijão caupi (FFCb). Sendo assim, o produto desenvolvido com a farinha de feijão caupi apresentou menor quantidade de umidade.

Quanto aos carboidratos, dentre as três formulações o que apresentou maior média foi a F1 $(57,56 \mathrm{~g})$ e a menor foi a F3 $(50,17 \mathrm{~g})$. No estudo de Marques et al., (2016), o qual desenvolveu uma formulação de cookies com adição de farinha de batata doce biofortificada, encontrou $62,62 \mathrm{~g}$ de carboidrato em seu estudo.

No quesito gorduras totais, a formulação apontou que F1 permaneceu com maior média, 19,41g e as formulações F2 e F3 mostraram a mesma porcentagem de gorduras, sendo a menor média 16,90. No estudo de Marques et al., (2016) citado acima, o autor encontrou em sua formulação uma quantidade de gorduras de 17,21\%, o qual mostra que as formulações desenvolvidas apresentaram menor quantidade em relação a porcentagem de gorduras.

Os teores de ferro e zinco foram mais elevados nas formulações dos biscoitos tipo cookies mostraram um aumento significativo com maiores percentuais de farinha de feijão F15\% e F30\%. Landim et.al (2013), em seu estudo de desenvolvimento de biscoitos com adição de farinha de feijão caupi, encontrou em suas formulações de farinha de feijão caupi (FFCb 30\%) um percentual de 7,7\% de ferro, o qual supre $77 \%$ das necessidades diárias. Já no quesito zinco, a formulação mostrou $5,4 \%$, suprindo $108 \%$ das recomendações. De acordo com a DRls, as quantidades diárias de ferro e zinco recomendadas para crianças e adolescentes de 9 a 13 anos são de $8 \mathrm{mg}$ e $7 \mathrm{mg}$ para ferro e 8-23mg de zinco. Nas formulações desenvolvidas de cookies, a formulação F2 supre $15 \%$ de ferro e $97,5 \%$ de zinco, já a formulação F3 supre $28,7 \%$ de ferro e $163 \%$ de zinco.

A Resolução № 54 de 12 de novembro de 2012 da ANVISA ainda diz que um alimento adicionado de minerais deve suprir de $15 \%$ a $30 \%$ da DRl's, o qual é considerado valor de referência para verificar a quantidade de vitaminas. Sendo assim, os biscoitos tipo cookies F2 e F3 apresentam valores iguais ou superiores aos recomendados pela resolução, podendo assim ser considerado uma fonte ferro e zinco e uma opção para suprir carências nutricionais de tais minerais.

\subsection{ANÁLISE SENSORIAL}

$\mathrm{Na}$ análise sensorial participaram 122 voluntários com idade entre 17 a 55 anos, com idade média de $23,5 \pm 6,4$ de ambos os gêneros. A análise sensorial consiste na interpretação de características sensoriais dos alimentos por meio de cinco sentidos: olfato, tato, visão, paladar e audição. Os resultados obtidos na análise sensorial estão representados na Tabela 04.

Segundo a análise de variância (ANOVA), as amostras dos cookies não tiveram diferença significativa $(p>$ ou $=0,05)$ quantos aos atributos de aparência, aroma e textura. Por outro lado, à média obtida no atributo de aceitação global apresentou diferença significativa de $(p<0,04)$, para o qual o teste de Tukey mostrou que as amostras $F 15 \%$ não diferiu dapadrão e a formulação $F 15 \%$ diferiu da $F 30 \%$. A maior média atribuída para a aceitação global foi a padrão e a menor média foi a de $30 \%$. 
Tabela 04. Resultados obtidos na análise sensorial das formulações de biscoitos tipo cookies com adição de farinha de feijão caupi Biofortificada:

\begin{tabular}{llllll}
\hline Atributos & FP & $\mathbf{F 1 5 \%}$ & $\mathbf{F 3 0 \%}$ & Valor P & DST \\
\hline Aceitação Global & $7,2 \pm 1,2^{\mathrm{a}}$ & $7,0 \pm 1,6 \mathrm{AB}$ & $6,7 \pm 1,8 \mathrm{~B}$ & 0,04 & 0,3994 \\
Aparência & $7,3 \pm 1,4$ & $7,2 \pm 1,6$ & $7,0 \pm 1,6$ & 0,17 & 0,2735 \\
Aroma & $7,9 \pm 6,4$ & $7,2 \pm 1,5$ & $7,1 \pm 1,7$ & 0,22 & 1,142176 \\
Sabor & $7,3 \pm 1,3 \mathrm{~A}$ & $7,1 \pm 1,6 \mathrm{AB}$ & $6,8 \pm 1,9 \mathrm{~B}$ & 0,02 & 0,39783 \\
Textura & $7,0 \pm 1,6$ & $7,0 \pm 1,8$ & $6,7 \pm 1,9$ & 0,61 & 0,053882 \\
\hline
\end{tabular}

* As Letras na mesma linha indicam que existe diferença estatística entre as amostras a 5\% de significância, segundo o teste de Tukey/ Fonte: Autora 2017.

Em estudos similares a este, Frota et al. (2010), cujo objeto da pesquisa foi utilizar a farinha de feijão caupi para desenvolvimento de produtos de panificação, com formulações de biscoitos com adição de 10, 20 e 30\% de farinha de feijão, observou que quanto aos atributos da análise sensorial os resultados foram similares ou maiores a este, que demonstrou, no quesito de aceitação global, resultado 7,0 para a formulação com $10 \%, 6,1$ para $20 \%$ e 6,0 para a formulação com $30 \%$. Com base nestes resultados observa-se que esta pesquisa está de acordo com a metodologia aplicados nas demais desta área.

Ainda, Lima et al (2011), que desenvolveu elaborações de pasteis de forno com a utilização de farinha de feijão caupi de duas variedades (MNCO5-828C-3-15) e (BRS Tumucumaque), com $20 \%$ de adição de farinha e obteve resultados na análise sensorial $(p<0,05)$ em todas as formulações nos atributos de aceitação global, 7,37 para a padrão e 7,93 para ambas as formulações. No quesito aroma, obteve 7,13 para a fórmula padrão, 7,57 para linhagem MNC05-828C-3-15 e 7,90 para a $B R S$ Tumucumaque. No sabor, 7,47 para padrão, 8,10 na linhagem MNC05-828C-3-15 e 7,9 na BRS Tumucumaque. Na textura, 7,37 para a padrão, 7,57 na linhagem MNCO5828C-3-15 e 7,9 na BRS Tumucumaque, porém pode-se observar que a maior nota de aceitabilidade foi atribuída para as formulações que continham a farinha de feijão.

Bauer (2014) desenvolveu uma pesquisa na qual teve por objetivo a utilização da farinha do bagaço da uva para formulação de biscoitos tipo cookies, sendo que a receita utilizava $10 \%$ de farinha de linhaça e $10 \%$ de farinha de uva. Ele observou, na análise sensorial, os seguintes resultados em relação ao atributo de aroma: 6,7 para a formulação $F 1$, com adição de farinha de linhaça e uva; 7,5 para a formulação com adição de $5 \%$ de farinha de uva e $10 \%$ de linhaça; e 7,1 para a formulação com $5 \%$ de adição de linhaça e $10 \%$ de farinha de uva, observando que a formulação dois obteve média de aceitabilidade maior em relação as demais formulações.

O índice de aceitabilidade das formulações dos tipos cookies está representado logo abaixo, na Tabela 05.

Tabela 05. Índice de aceitabilidade das formulações de Biscoitos tipo cookies com adição de farinha de feijão caupi biofortificada:

\begin{tabular}{lccc}
\hline Atributos & F1 & F2 & F3 \\
\hline Aceitação Global & 80 & 77 & 74 \\
Aparência & 81 & 80 & 77 \\
Aroma & 87 & 80 & 78 \\
Sabor & 81 & 78 & 75 \\
Textura & 77 & 77 & 74 \\
Média IA \% & $81,2 \%$ & $78,40 \%$ & $75,60 \%$ \\
\hline
\end{tabular}


Para ser considerado como um produto bem aceito quando se diz em análise sensorial, é necessário que o produto obtenha um percentual de no mínimo $70 \%$ de aceitabilidade (SCHEFFER, 2010). Sendo assim, as formulações de biscoitos tipos cookies com adição de $15 \%$ e $30 \%$ de farinha de feijão mostraram uma porcentagem satisfatória e um bom índice de aceitabilidade.

O surgimento de novos produtos vem sendo considerado como uma importante fonte de sustentação para as indústrias, as quais, ao lançar novos produtos, aumentam sua participação no mercado, melhorando seus lucros e rentabilidade (LUGOBONI, 2013).

Em um estudo similar a este, Frota et.al (2010) desenvolveu produtos de panificação com a adição de farinha de feijão caupi, no qual pode-se observar que no quesito aceitabilidade sua maior média foi atribuída a formulação padrão: $88,9 \%$. Já para as formulações de biscoitos com adição de 10, 20 e 30\% de farinha de feijão, sua maior aceitabilidade foi a formulação com a adição de $10 \%$ de farinha de feijão aos biscoitos, com resultado de $84,4 \%$. Sua menor aceitabilidade para a formulação com $30 \%$ foi de $62,2 \%$. As médias atribuídas a intenção de compra das formulações de cookies com farinha de feijão caupi biofortificado estão apresentadas na figura 2.

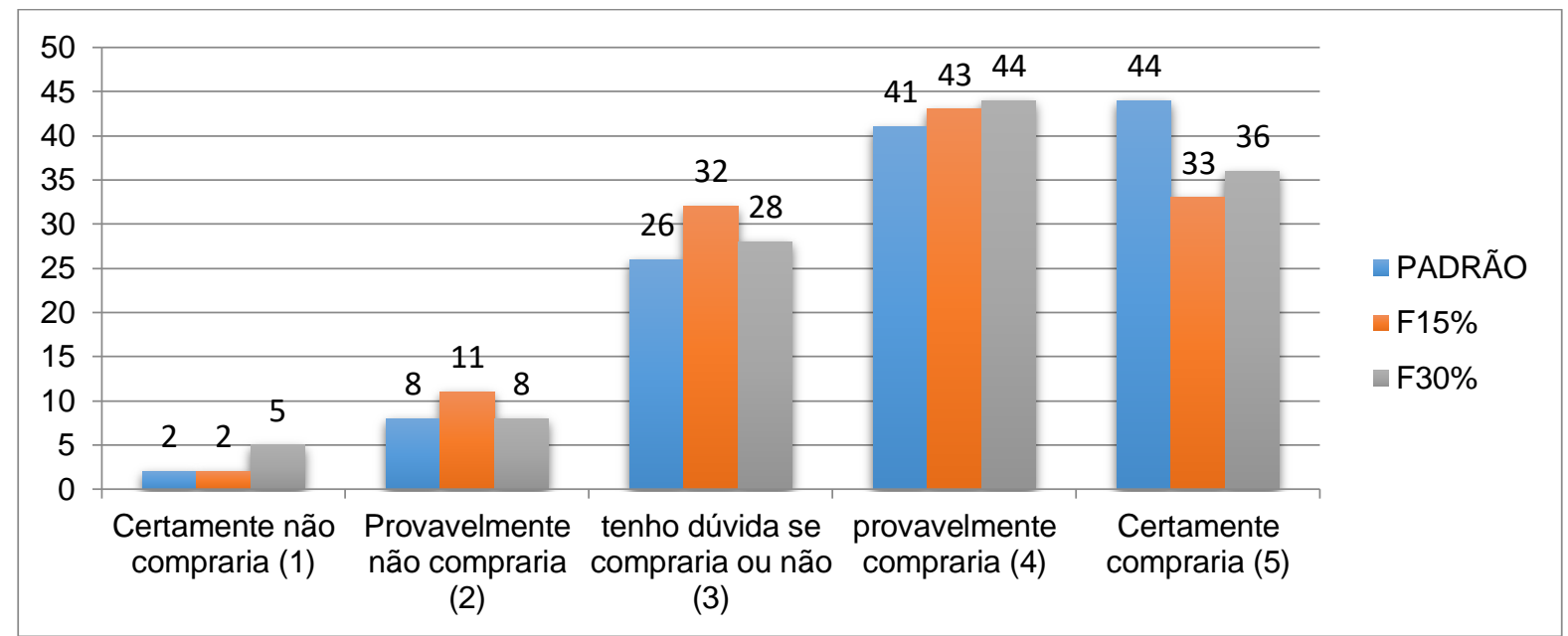

Figura 2. Média de intenção de compra das amostras de cookies com adição de farinha de feijão caupi biofortificados:

As notas atribuídas foram estruturadas com notas de 1 até 5 , sendo 1 para "certamente não compraria" e 5 para "certamente compraria". Em relação ao teste de intenção de compra, notou-se que os produtos avaliados (padrão, F15 e 30\%). Os quesitos das médias entre as notas 4 e 5, provavelmente compraria e certamente compraria, se destacaram dentre os demais dados. Desta forma, pode-se afirmar que os produtos desenvolvidos tiveram boa aceitação e possivelmente teriam sucesso comercial, além de serem produtos mais nutritivos.

\section{CONSIDERAÇÕES FINAIS}

Os cookies desenvolvidos apresentaram aceitação semelhante ao padrão. Em relação à composição centesimal, os teores de fibra aumentaram significativamente. Os teores dos minerais ferro e zinco tiveram um aumento significativo com a adição da farinha de feijão caupi. Os atributos sensoriais de aparência, aroma e textura não apresentaram diferenças. Por outro lado, os atributos de aceitação global e aroma 
diferiram entre as amostras, constatando que em um dos biscoitos tipo cookies foi perceptível para os provadores a adição de farinha de feijão.

Portanto, conclui-se que os cookies desenvolvidos com adição de farinha de feijão caupi biofortificado apresentaram resultados satisfatórios principalmente a formulação $\mathrm{F} 15 \%$, os quais os participantes não perceberam a adição da farinha quando comparada com o produto já existente na indústria alimentícia. Sendo assim, é possível desenvolver um alimento mais saudável para a população, com maior quantidade de micronutrientes, essenciais para a manutenção da saúde, além de ser uma nova opção para a indústria alimentícia, oferecendo aos seus consumidores alimentos mais saudáveis e nutritivos.

\section{REFERÊNCIAS BIBLIOGRÁFICAS}

ANVISA - Agência Nacional de Vigilância Sanitária. Resolução RDC nํ 12, de 02 de janeiro de 2001. . Disponível em: <http://portal.anvisa.gov.br/documents/33880/2568070/ RDC_12_2001.pdf/15ffddf63767-4527-bfac-740a0400829b.>. Acessado em: 06 de junho de 2017.

ANVISA - Agência Nacional de Vigilância Sanitária. Resolução RDC no 263, de 22 de setembro de 2005. Disponível em: <http://www.saude.rj.gov.br/comum/code/ MostrarArquivo.php? =MjlwMw\%2C\%2C.> Acessado em 06 de junho de 2017.

ANVISA- Agência Nacional de Vigilância Sanitária. Ministério da Saúde - Resolução da diretoria colegiada - RDC no 54, de 12 de novembro de 2012. Disponível em: $<$ http://portal.anvisa.gov.br/documents/\%2033880/2568070/rdc0054 1211 2012.pd f/c5ac23fd-974e-4f2c-9fbc-48f7e0a31864. . . Acessado em 12 de julho de 2017.

BAUER,V.F. Elaboração de Biscoitos tipo cookies com a utilização de farinha extraída do bagaço da uva. Dissertação Pós-Graduação da Universidade Federal do Rio Grande do Sul, Porto Alegre- RS, 2014.

BARBOSA, Z. de M. C.D. Seleção de linhagens elite de feijão caupi (vigna unguiculata (I.) walp.) para biofortificação de ferro e zinco. Dissertação de PósGraduação da UNIVERSIDADE FEDERAL DO PIAUÍ - UFPI, Terezina- PI, 2015.

CARDOSO SANTIAGO, R. A.; MOREIRA ARAUJO, R. S. R.; ARÊAS, J. A. G. Thepotencial of extruded chickpea, corn and bovine lung for malnutrition program. Innovative Food Science and Emerging Technologies, v. 2, n. 3, p. 203-209, 2001.

CARVALHO et al. Obtenção de populações de feijão caupi visando a biofortificação para os teores de ferro, zinco e proteína. In: Reunião de Biofortificação no Brasil, 4, 2011. Teresina.

DUTCOSKY, S. D. Análise sensorial de alimentos. 4. ed. rev. e ampl. Curitiba: Editora: Champagnat, 2013. 
FISBERG, M. A; VELLOZO, E. P.contribuição dos alimentos fortificados na prevenção da anemia ferropriva. Revista Brasileira de Hematologia e Hemoterapia, São Paulo, v. 32, n. 2, p. 140-147, maio 2010.

FRANCO, B,D,GM.; LANDGRAF M. Microbiologia dos Alimentos. Atheneu, 1996.

FREITAS, R. M. O. de. Ecofisiologia de feijão-caupi submetido a deficiência hídrica nos sistemas de plantio direto e convencional. 2015. $62 \mathrm{f}$. Tese (Doutorado) - Curso de Agronomia, da Universidade Federal Rural do Semi Árido, Mossoró, 2015.

FILHO et al. Novo gene produzindo cotilédone verde em feijão caupi. Rev. Ciência Agronômica, v.38, n.03, p. 286- 290, 2007.

FILHO et al. Panorama da Cultura do Feijão Caupi no Brasil- Workshop sobre a Cultura do Feijão-caupí em Roraima, 2007.

FROTA, K.M.G et.al. Utilização da farinha de feijão-caupi (VignaunguiculataL. Walp) na elaboração de produtos de panificação. Ciênc. Tecnol. Aliment., Campinas. 2010.

FROTA, K. M. G.; SOARES, R. A. M.; ARÊAS, J. A. G. Composição química do feijão caupi (Vigna unguiculata L. Walp.). Cultivar BRS- Milênio. Rev. Ciência e Tecnologia de Alimentos, Campinas, v.28, n.2, p.470-476, 2008.

GONÇALVES et al. Uso da biofortificação vegetal: uma revisão. Rev. Centro Universitário de Patos de Minas. ISSN 2178-7662. Patos de Minas, UNIPAM, (6): 7587, dez. 2015.

IAL (INSTITUTO ADOLFO LUTZ). Normas Analíticas do Instituto Adolfo Lutz: Métodos físico-químicos para análise de alimentos. Instituto Adolfo Lutz. São Paulo, 2008.

LANDIM, Liejy Agnes dos Santos Raposo. Utilização de biscoito enriquecido com feijão-caupi (vignaunguiculata (I.) walp) biofortificado em pré-escolares para controle da anemia ferropriva. 2013. $94 \mathrm{f}$. Dissertação (Mestrado) - Curso de Nutrição, Universidade Federal de Piaui, Teresina, 2013.

LEITÃO, W. de Sousa; OLIVEIRA, E. de - Anemia Ferropriva infantil no Brasil: Uma revisão sistemática da Literatura. Revista Científica Multidisciplinar Núcleo do Conhecimento. Ano 1; Vol. 5; pp - 24 36, Julho, 2016. ISSN 2448-0959

LEMOS,S.B; LIBERALI, R; COUTINHO V.F; ASSUMPÇÃO C,O. Biodisponibilidade de ferro e a anemia ferropriva na infância- Ensaios e Ciência: Ciências Biológicas, Agrárias e da Saúde, vol. 16, núm. 4, 2012, pp. 213-228.

LIMA et al. Obtenção e utilização de farinha de feijões-caupi de grãos brancos na elaboração de pastel de forno. III Congresso Nacional de feijão caupi. Recife-PE, 2013. 
LUGOBONI et al. Lançamento de novos produtos no segmento alimentício B2B: uma comparação as ações realizadas pelo mundo. Salvador- BA, 2013.

MACFIE, H. J.; BRATCHELL, N.; GREENHOFF, K.; VALLIS, L. V. Designs to balance the effect of order Of presentation and first-order Carry-over effects in hall tests. Journal of Sensory Studies, 1989.

MALHEIRO, M. G.; MORGADO, L. B.; KIILL, L. H. P. Ecologia da polinização do feijão-caupi (vigna ungulculata (I.) walp.) em área de sequeiro no Municipio de Petrolina-PE. Congresso Nacional de Botânica 2008. Disponível em: $<$ https://www.embrapa.br/busca-de-publicacoes/-/publicacao/161512/ecologia-dapolinizacao-do-feijao-caupi-vigna-ungulculata-l-walp-em-area-de-sequeiro-nomunicipio-de-petrolina-pe. $>$. Acesso em 11 de julho de 2017.

MARQUES et al. Produção de cookies a partir da farinha de batata doce biofortificada com betacaroteno. XXV Congresso Brasileiro de Ciência e Tecnologia de Alimentos. Gramado-SC 2016.

MARQUES et al. Fortificação de alimentos: uma alternativa para suprir as necessidades de micronutrientes no mundo contemporâneo. Rev.HU, Juiz de Fora, v. 38, n. 1, jan./mar. 2012.

NUTTI, M. R. Biofortificação no Brasil: Desenvolvendo Produtos Agrícolas Mais Nutritivos. Embrapa Agro de Alimento. Rio de Janeiro, 2011.

OLIVEIRA, D. A. V. de. Caracterização química, minerais, tempo de cocção e produtividade de genótipos de feijão-caupi- Dissertação, Mestrado- Universidade federal do Piauí - UFPI, Teresina -PI 2016.

PEDRAZA, D.F; SALES, M.C. Deficiência de zinco: diagnóstico, estimativas do Brasil e prevenção. Rev. Nutrire. Natal- RN, 2015 Dec;40(3):397-408.

ROCHA et al. Estimativas de parâmetros genéticos (G), ambientais (A) e da interação $G \times A$ para os conteúdos de ferro e zinco em germoplasma elite de feijão caupi. REUNIÃO ANUAL DE BIOFORTIFICAÇÃO NO BRASIL, 3., 2009, Aracaju.

SILVA, N.; JUNQUEIRA, V.C.A.; SILVEIRA, N.F.A. Manual de Métodos de Análise Microbiológica de Alimentos. $4^{\mathrm{a}} \mathrm{ed}$. São Paulo: Editora Varela, 2010 